\title{
A MODIFIED TECHNIQUE FOR STAINING LEPROSY BACILLI IN SMEARS
}

\author{
R. RHODES-JONES
}

(From the laboratories of the East African Leprosy Research Centre, P.O. Box 1044, Busia, Tororo, Uganda)

The following method of acidfast staining of $M$. leprae has the advantage of timed decolourising, and so gives consistent results.

\section{Method}

All staining is carried out in Coplin jars.

(a) Flame fix.

(b) Stain with Ziehl-Neelsen stain at room temperature for 20 minutes.

(c) Wipe stain from the back of the slides and wash in tap water.

(d) Decolourise in $5 \%$ sulphuric acid for five minutes.

(e) Wash well in running water.

(f) Counterstain with $0.1 \%$ toluidin blue for one minute. Wipe off any excess stain from the back of the slide and blot dry.

Methylene blue $0.1 \%$ may be used instead of toluidin blue. The author prefers the latter as it gives a clearer background.

This method has now been in used in this Research Centre for the last ten months, with excellent and consistent results.

\section{Acknowledgement}

I wish to thank the Administrator, East Africa High Commission, for permission to publish this paper. 